University of Nebraska - Lincoln

DigitalCommons@University of Nebraska - Lincoln

1986

\title{
Results and Interpretations from a Survey on Agriculturally Related Weather Information
}

A. Weiss

J. G. Robb

Follow this and additional works at: https://digitalcommons.unl.edu/panhandleresext

This Article is brought to you for free and open access by the Agricultural Research Division of IANR at

DigitalCommons@University of Nebraska - Lincoln. It has been accepted for inclusion in Panhandle Research and Extension Center by an authorized administrator of DigitalCommons@University of Nebraska - Lincoln. 


\section{Results and Interpretations from a Survey on Agriculturally Related Weather Information}

\begin{abstract}
A survey of "top" wheat farmers in 12 counties in western Nebraska was undertaken to help guide future research and extension programs (in agricultural meteorology and economics) in the region. One hundred forty-two farmers ( 59 percent of those receiving questionnaires) responded to the survey. Of the respondents, 42 percent own or are considering purchasing a personal computer; the vast majority of farmers own a rain gage and some form of temperaturemeasuring device; the respondents were moderately familiar with an existing Automated Weather Data Network in Nebraska; commercial and NOAA weather radio and commercial television are the main sources of weather data and information; short-term weather forecasts ( 1 day and 3-5 days) are most important to overall farm planning; respondents considered market and cost-of-production information and more-accurate weather forecasts most important in better management of their farm operations; the risk factors that impacted farm net income were economic followed by weather factors and marketing decisions; and most farmers would be willing to forward contract before the crop was half developed if good projections of crop status and yield could be made. A major constraint to preharvest forward contracting from some of the farmers' perspective appears to be variability in yield due to hail.
\end{abstract}

\section{Introduction}

“Agriculture is the Nation's biggest industry. Its assets, totaling $\$ 1,090$ billion on January 1,1981 , are equal to about 88 percent of the capital assets of all manufacturing corporations in the United States" USDA (1981). Little else needs to be said about the importance of agriculture to the United States or to other nations of the world.

Until recently, the image of the United States farmer has been of a person in bib overalls, chewing on an alfalfa stem, and leading a self-reliant life in a rural environment. The image is changing as articles in the popular press (Wall Street Journal, between 9 and 23 November 1984) depict successful modern agriculture as a capital-, technology-, and management-intense industry.

This survey was undertaken to determine the weather data and weather-related informational needs of wheat farmers in western Nebraska as an input to development of research and extension programs in agricultural meteorology and economics.

It is necessary to distinguish between data and information. Examples of the former are 78, 17, and 323 (with appropriate units), while the latter can be represented by the phrase ". . given past and future weather conditions the effect of

${ }^{1}$ Published as paper 7678, Journal Series, Nebraska Agricultural Research Division.

(C) 1986 American Meteorological Society

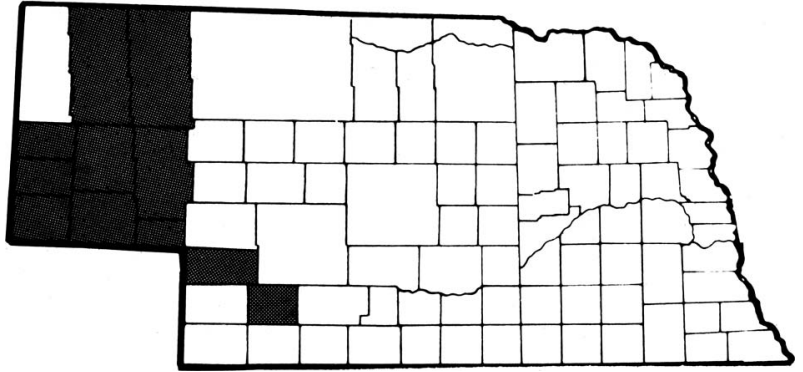

FIG. 1. Map of Nebraska with participating counties shaded.

pesticide $x$ on pest $y$, which can now have a serious economic impact on crop $z$, can be 80 percent effective if action is taken within the next three to five days ..." Data are merely numbers, while information can be used as a basis for decisions. Our interest in this survey was not only in meteorological data and methods of dissemination of weather-related information, but in the types of information that those surveyed considered important. Previous surveys, e.g., Getz (1978), Johnson and Perry (1983), and Vining et al. (1984), have concentrated only on weather data and mechanisms of effective distribution.

Weather conditions can have a direct impact on foliar diseases and utilizing this fact can lead to successful control programs (e.g., Blackman et al., 1984; Nutter et al., 1983). Based on a survey of tobacco farmers in eastern North Carolina, Kirby et al. (1983) reported that farmers routinely apply pesticides as a form of "insurance" as part of their management scheme. With the ever-increasing concern about the environment, situations as reported by Kirby et al. will eventually change to a different type of management system.

\section{Materials and methods}

Fifteen counties in western Nebraska were selected for this study. Rather than using a random survey and trying to draw implications for the region, we decided to focus on a subset of "top" farmers. County Extension Agricultural Agents were asked to supply one name from "a 'top farmer' target group" for each 2024 hectare (ha) of wheat harvested in 1981 in their county. "Innovators," the most eager to try new ideas, and "early adopters," the next group in the diffusion chain of new ideas, are approximately 2.5 and 13.5 percent of the farm population, respectively (Rodgers, 1983; Bohlen et al., 1961). Although these types of farmers may only represent a small part of the farming population, this small group leads in bringing new technology to agriculture. 
Thus, they are the group that often indicates future trends that may be adopted by the majority of farmers.

Three hundred names were requested from 15 counties. Responses were received from the 12 counties shown in Fig. 1, resulting in 239 usable names. Of the 239 questionnaires sent out, 142 (59 percent) were returned. This high rate of response (the expected response to this type of survey is about 30 percent; Vining et al., 1984) indicates that the survey generated considerable interest in the area of weather-related information.

Though questions were phrased in terms of the last five years, this survey represents, as any survey does, a specific response period; in this case from March to May 1984. Relatively recent events may have had a greater influence on those being surveyed than events at the beginning of the time period. Extrapolation of results specific to wheat to other crops may not be valid, whereas results pertaining to weather data and weather-related information may have general implications.

\section{Results and discussions}

The first five questions of this survey (see Appendix) were designed to provide background information on the respondents. In the subsequent questions, the respondents were asked to rank or select answers. Space was provided for comments, which were encouraged.

Question 1. Size of Wheat Operation: The average wheat area harvested per year was 380 ha. These results were distributed in increments of 162 ha as follows: 19 percent of the respondents harvested less than 161 ha, 34 percent harvested $162-323$ ha, 32 percent $324-485$ ha, and 15 percent more than 486 ha.

Question 2. Geographic Area: Zip code was requested so that responses could be sorted by geographical area. While we did sort some of the responses by area, no additional insights were gained.

Question 3. Years of Experience: This question appeared to be vague, resulting in different interpretations of "experience." It was obvious that some people considered experience in wheat farming beginning at or shortly after birth, while others considered it to be when full-time farming began. These different interpretations resulted in an average of 29 years' experience in wheat farming.

Question 4. Crop Rotation: Slightly over 75 percent of the respondents indicated the traditional wheat-fallow rotation as their primary crop-rotation system. The eastern boundary of the survey area receives more precipitation than the western portion. This accounts for use of other rotations, mostly the wheat-corn-fallow rotation. Some farmers do not have standard rotations and seven respondents commented that government programs influence their cropping sequence.

Question 5. Farm Computers: Twenty-four percent (34) of the farmers surveyed indicated that they have a small computer on their farms. In a random survey, based on 371 respondents, of farms and ranches throughout Nebraska (Rockwell and Goding, 1984), only 3 percent reported ownership of small or personal computers. This eightfold difference in computer ownership supports our assumption that the former group represents "top" farmers. In addition, another 18 percent ( 25 farmers) indicated that they have considered purchasing a small computer for their farm.

Questions 6 and 7. Weather Instruments: A rain gage was owned by 96 percent (137) of the farmers, while only 1 percent ( 1 farmer) owned no meteorological sensor. Ownership of window thermometers, max-min thermometers, and windmeasuring devices was reported by 87 (124), 18 (26), and 8 (12) percent (number) of the respondents, respectively. Twenty-six percent (37) of the farmers had some sort of soilmoisture measuring device. The majority of these devices were probes, gypsum blocks, or tensiometers. One farmer used an evaporation pan.

Questions 8 and 9. Automated Weather Data Network: Familiarity with the Automated Weather Data Network (AWDN), a computer-linked network of automated weather stations located throughout Nebraska (Hubbard et al., 1983), was indicated by 19 percent (27) of the respondents. Two people felt that the data were very representative of their farm, nine cited mostly representative, 13 cited slightly representative, one cited not representative, and two didn't know. Of those familiar with the network 26 percent (seven farmers) had used it. Principal uses of data from this network were in irrigation scheduling or in cattle feeding. One respondent followed soil-temperature reports from the network for planting purposes and kept track of growing degree days. A possible explanation for this lack of awareness about the AWDN may be its relatively recent implementation in some cropping areas of western Nebraska. The data from the AWDN are available on AGNET, a time-share mainframe computer system, and are used in some AGNET programs. Originally developed at the University of Nebraska, AGNET has evolved into one of several multistate agricultural-information and data-delivery systems in the nation.

Question 10. Sources of Weather Data and Information: The most popular methods of receiving weather data and information were commercial radio, commercial television, and NOAA weather radio. Combining highest rankings ( 1 or $2)^{2}$ the percent (number) of people who rated these sources as most used was 78 (111), 61 (87), and 38 (54), respectively. A survey by the General Accounting Office (Eschwege, 1979) obtained similar results concerning radio and television. In contrast, Vining et al. (1984) found that television was ranked first and radio second by the respondents to their survey.

Question 11. Important Forecast Intervals: The weather forecasts found most important by the respondents were short-term in nature: 3-5 day forecasts (67 percent or 111 of the respondents), 1-day forecasts ( 21 percent or 30 respondents), 30-day forecasts ( 11 percent or 16 respondents), and 90-day forecasts (1 percent or 2 respondents).

Question 12. Controllable Wheat Losses: The percent of the farmers' weather-related wheat losses due to potentially controllable weather-influenced factors followed a skewed distribution, as shown in Fig. 2. On the average, farmers estimated losses due to these types of factors (insects, diseases, weeds, etc.) to be about 13 percent. However, 6 percent of the

\footnotetext{
${ }^{2}$ This rating uses the sum of those who ranked 1 or 2 divided by the number who responded to the question, expressed as a percentthus summation of reported percentages may exceed 100 percent.
} 


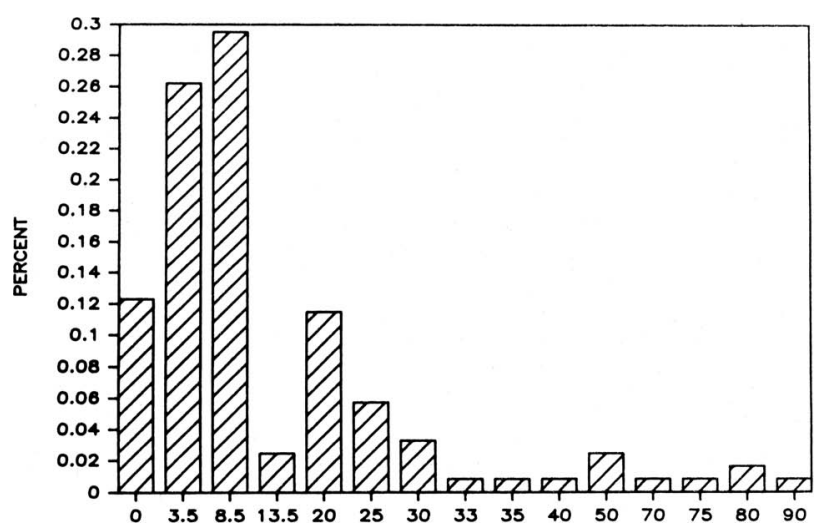

FIG. 2. Distribution of potentially controllable losses due to insects, diseases, or weeds. The $x$-axis is the percent of crop loss, while the $y$-axis is the percent of farmers in each crop loss class.

farmers who responded to this question estimated losses greater than 50 percent.

Question 13. Important Management Information: Combining highest rankings ( 1 or 2), 72 percent or 102 farmers felt that market and cost-of-production information was most important to better management of their farms. Interest in this type of information is not unique; as Schuh (1984) notes, "Every survey of farmers I have seen has found them asking for more help on marketing problems, on their financial management problems, on agricultural policies, and on trade problems." Rated a close second, by 66 percent or 94 farmers, was more-accurate weather forecasts. Thirty-three percent or 47 farmers ranked forecasts of pest populations and only 9 percent or 13 farmers ranked forecasts of local yields before harvest as 1 or 2 . Seven percent or 10 farmers ranked "other" as their first or second choice, but upon examination these responses generally could have been included into the two most popular categories.

Question 14. AGNET Use: Twenty-two percent or 31 farmers surveyed have used AGNET within the last year, and 26 percent of these users have a private account. A survey (Rockwell and Goding, 1984) of the general farm population in Nebraska found that only 13 percent of those familiar with AGNET had used it. The farmers surveyed here, compared to the general farm population, again tend to be in a "top" farmer group willing to try new data- and informationdissemination methods. In this survey, of those who are not currently subscribers, 37 percent ( 53 farmers) would be willing to subscribe to AGNET for access to good-quality weather-related information and related farm-management programs. We assume this group of farmers was aware of the fees associated with AGNET.

Question 15. Risk Influences on Expected Net Income: Farmers were given seven risk factors to rank based on their experience during the last five years. Economic considerations dominated these responses. Combining the highest two rankings, farmers cited financial costs and economic trends (67 percent or 95 farmers) or fluctuating market prices (60 percent or 85 farmers) as risk factors making the greatest impact on their net income. Uncontrollable weather-related risks (hail, drought, or flooding) were listed as one of the two top risk factors by 47 percent or 67 farmers, while lack of soil moisture was listed by 23 percent or 32 farmers. The difference between drought and lack of soil moisture is one of degree, but was not made clear in the survey question.

Question 16. Positive Influences on Expected Net Income: In contrast to the risk factors influencing net farm income, weather-related factors during the last five years have led to better-than-expected net farm income. Seventy-three percent or 104 farmers ranked soil moisture and climate as either the first or second most important factor. Forty-nine percent or 74 farmers ranked good marketing decisions as either the first or second most important factor. Selection of plant variety (42 farmers) and government programs (37 farmers) were each ranked 1 or 2 by just under 30 percent of the respondents.

Question 17. Forward Contracting, Crop Development, and Yield Estimates: Forward contracting is the process of establishing price and, usually, a specific quantity of the crop for future delivery between a buyer and a seller. This question specifically asked about contracting during the growing season, involving an added dimension of production risk, compared to a crop in storage. The two typical types of forward contracting, from the farmer's perspective, are with a local elevator or with hedging using the futures market.

Not all those surveyed responded to this question. Of those who did, (128 farmers), most would, if crops status and yield could be accurately projected, be willing to forward contract before the crop is harvested. Of the respondents, 21 (28), 45 (57), 19 (24), and 15 (19) percent (farmers) would be willing to consider forward contracting the crop, given the assumed information, at 10, 40, 80, and 100 percent of crop development, respectively. Of the farmers requiring 100 percent crop development (not willing to consider a forward contract), most commented on the high potential of hail damage to their crops.

The final question was a call for comments. Responses covered a spectrum of problems and opinions, e.g., accuracy of local weather forecasts, importance of using proper plant variety, alleged negative impact on commodity prices by futures trading, and positive and negative aspects of government programs. Many people requested a copy of the survey results.

\section{Interpretations and conclusions}

A survey was evaluated on weather-related information for "top" wheat producers in western Nebraska. The results of this survey indicate the producer's desire for integrating quality weather-related information into farm production and management. There also appears to be a willingness to subscribe (pay) for this type of information. If the farmers surveyed here are an indicator, the number of farmers who would be willing to pay for such information will increase as the economics of farm production and management assumes a greater role in farm viability and profit. The respondents had a high use of and interest in small computers (question 5), but little interface with the existing computer time-share system available in Nebraska (question 14).

Farmers found short-term weather forecasts, especially 3-5 day forecasts, most valuable in their overall farm plan- 
ning. The short-term forecasts provide an important data source for farmers with which to make a decision. For example: if cool, damp weather is predicted and there is a possibility of a fungal disease outbreak, it is important that all spray equipment is in operating condition and adequate supplies of fungicide are available. While all farmers are presented with the same data, the resulting information may be different for each farm and weather scenario.

Radio and television provide short-term useful-life forecasts and were highly ranked in importance. Radio, because it is used in tractors, pickup trucks, and cars, was almost twice as popular as television as a source of weather data and information. Another reason for radio's popularity is that the necessary data are given often and the reports are short. The radio is also a source of other agricultural data, such as the latest commodity prices, that are necessary inputs to modern farm decision making. Commerical and noncommercial television (such as "AM Weather," a program produced by NOAA for pilots) is important because it pictorially shows present and future weather conditions.

The majority of producers do not perceive substantial weather-related losses as being due to potentially controllable weather-influenced factors such as insects, diseases, etc. Although these producers may be considered "top" farmers, the importance of weather interactions in these factors may not be well understood. Direct severe-weather factors such as drought, hail, etc., were cited by almost half the producers as a major risk factor influencing net income.
Yield projections from crop models appear to be viewed as data rather than as information. The results of question 17 contrast with responses to question 13 , which suggested that little value was attached to forecasting yields in advance. A reason for this apparent incongruity may be that predicted crop yields are data and only become useful information when related to farm management/marketing decisions. When put into a marketing-decision framework, producers showed a strong response to using this information by forward contracting the crop before harvest. Comments from farmers and the number of respondents who ranked severe weather as important risk factors (such as drought, hail, etc.) imply that future crop status and yield models should give consideration to modeling these risk factors.

A role for agricultural meteorologists, in this era of information technology, is to develop models of crop development and yield with sufficient sophistication to take into account potential production risks. For various levels of resource, management ability, and risk aversion, agricultural economists should investigate which production and marketing strategies yield the best economic results in terms of profit and survival.

Acknowledgments. We want to thank all the wheat growers who participated in this survey. Drs. N. J. Rosenberg, L. L. Bitney, and the three anonymous reviewers provided valuable comments during the preparation of this article.

\section{Appendix. Weather-Related Information for Wheat Production Survey}

We need some background information to classify survey responses, please answer the following:

ANSWER

1. How many acres of wheat do you harvest in an average year?

2. Zip code of your farm location

3. Years of experience in farming wheat

4. Please describe your wheat-fallow or other crop rotation program

5. Do you have a small computer for your farm? -If no, have you considered purchasing a small computer for your farm?

The following questions will provide input to research and extension programs of the University of Nebraska in western portions of the state. Many questions have space provided for your comments. We encourage your comments.

6. Which of the following weather instruments do you own? (Please circle)
a) none
d) maximum-minimum thermometer
b) raingage
c) window thermometer
e) wind measuring device

7. Do you have a soil moisture measurement instrument?

-If yes, please describe

8. Are you familar with the Automated Weather Data Network in Nebraska? 
9. If you are aware of the Automated Weather Network in Nebraska, is the nearest station representative of conditions on your farm? (Please circle one only)
a) very representative
d) not representative
b) mostly representative
e) don't know
c) slightly representative

10. Please rank the following sources of weather data and information assigning " 1 " for the most important source, and " 2 " for the second most important, etc.:
a) commercial radio broadcasts
b) special telephone forecast
c) television broadcasts
d) NOAA weather radio - weather alert radio
e) Extension services (AGNET, AGRI-VIS, etc.)
f) newspaper
g) personal knowledge (own or of others)
h) other

11. Which of the following weather forecasts have you found most valuable in your overall farm planning? (Please circle response)
a) 1 day forecast
c) 30 day forecast
b) 3-5 day forecast
d) 90 day forecast

12. What percent of your weather related wheat losses over the last 5 years are due to potentially controllable weather influenced factors, such as insects, weeds, diseases, etc. (Percent out of $100)$ ?

13. To better manage your farm, what type of information is the most important to you? (Please rank in order of importance, with " 1 " a the highest, then " 2 ', etc.)

a) more accurate weather forecasts

b) forecasted local yields before harvest

c) forecasted pest populations

d) market and cost of production information

e) other

14. Have you used AGNET in the last year?

-if yes, does your farm have a private account?

-if no, would you be willing to subscribe to get good quality weather related information and related farm management programs?

15. Based on your experience as a wheat farmer during the last five years, rank the following risk factors according to their impact on your net income. (Use a "1" for the most important influences, " 2 " for the second most important, etc.)
a) financial costs and economic trends
b) fluctuating market prices
c) weeds, diseases, insects
d) lack of soil moisture
e) hail, drought, flooding, etc.
f) lack of water in wells for irrigation
g) other

16. Based on your experience as a wheat farmer during the last five years, rank the following according to their influence in getting better than expected net income. (Use a "1" for the most important, " 2 " for the second most important, etc.)

$R A N K$

$R A N K$

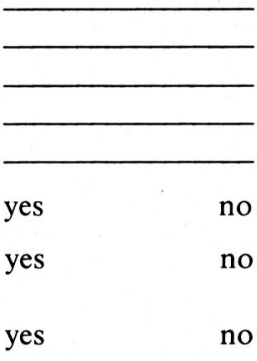

RANK

a) government programs

b) soil moisture and climate

c) low pest populations 
d) good marketing decision

e) selection of plant variety

f) use of management recommendations from others

g) other

17. At what percent of crop development would you consider forward contracting before harvest if you could accurately project crop status and yield? (Please circle only one.)
a) $10 \%$
b) $40 \%$
c) $80 \%$
d) $100 \%$

18. Thank you, if you have any additional comments relating to this survey, please use the space below or use a separate page.

\section{References}

Blackman, P. A., M. A. Crawford, and J. M. Hammond, 1984: Comparison of meteorological and standardized timings of fungicide applications for soybean disease control. Plant Dis., 68, 44-46.

Bohlen, J. M., C. M. Coughenour, H. F. Lionberger, E. O. Moe, and E. M. Rodgers, 1961: Adopters of new farm ideas. North Central Regional Extension Publication No. 13, 12 pp.

Eschwege, H., 1979: Agricultural weather information is not effectively communicated to users. GAO Rept. CED-79-110, 27 pp.

Getz, R. R., 1978: A survey of New Jersey's agricultural weather service users. Bull. Amer. Meteor. Soc., 59, 1297-1304.

Hubbard, K. G., N. J. Rosenberg, and D. C. Nielsen, 1983: Automated weather data network for agriculture. J. Water Resour. Plan. Manage., 109, 213-222.

Johnson, G. L., and K. B. Perry, 1983: Broadcaster's use of agricultural weather products: A North Carolina survey. Bull. Amer. Meteor. Soc., 64, 1026-1028.
Kirby, H. W., C. E. Main, and G. A. Carlson, 1983: Biological and economic factors influencing farmer acceptance of pest management practices. Plant Dis., 67, 1095-1099.

Nutter, F. W., H. Cole, Jr., and R. D. Schein, 1983: Disease forecasting system for warm weather Pythium blight of turfgrass. Plant Dis., 67, 1126-1128.

Rockwell, S. K., and M. Goding, 1984: The use of AGNET and microcomputers, $16 \mathrm{pp}$. [Available from the senior author at the Cooperative Extension Service, University of Nebraska, 221 Agricultural Hall, Lincoln, NE 68583-0703.]

Rodgers, E. M., 1983: Diffusion of Innovations. The Free Press, New York, N.Y. 453 pp.

Schuh, G. E., 1984: Agricultural research: How it should be affected by exports. Agric. Engr., 65, 8-12.

USDA, 1981: Fact Book of U.S. Agriculture, Misc. Publ. No. 1063, $133 \mathrm{pp}$.

Vining, K. C., C. A. Pope III, and W. A. Dugas, Jr., 1984: Usefulness of weather information to Texas agricultural producers. Bull. Amer. Meteor. Soc., 65, 1316-1319.

\section{announcements}

\section{European Weather Centre Celebrates Anniversary}

The European Centre for Medium Range Weather Forecasts (ECMWF), situated near Reading, England, celebrated its 10thyear anniversary on 22 November 1985. The ECMWF is an international organization supported by 17 European countries. The objectives of the ECMWF include the development of numerical methods for weather prediction and the provision of operational medium-range forecasts to the meteorological services of member states. The ECMWF recognized 10 years of fruitful European cooperation and achievement in weather forecasting by hosting a scientific seminar on the day of its anniversary.

\section{AAUW Announces Fellowship Competition}

The American Association of University Women (AAUW) is now offering fellowship opportunities to American women for advanced study, research, and community projects. The AAUW

\footnotetext{
${ }^{1}$ Notice of registration deadlines for meetings, workshops, and seminars, deadlines for submittal of abstracts or papers to be presented at meetings, and deadlines for grants, proposals, awards, nominations, and fellowships must be received at least three months before deadline dates.-News Ed.
}

is now offering postdoctoral, dissertation, and selected-profession fellowships to women who are citizens of the United States and who have achieved distinction in their fields. Awards range from $\$ 3500$ to $\$ 9000$ for one academic year. Applicants must be ready to begin their degree program in the fall following their application. For more information or an application, contact American Fellowships, AUWW Educational Foundation Programs Office, 2401 Virginia Avenue, N.W., Washington, DC 20037.

\section{meetings of interest}

14-16 March 1986. The AMS Lyndon State College student chapter is sponsoring the Eleventh Annual Northeastern Storm Conference on 14-16 March 1986 in Windsor Locks, Connecticut. The guest speaker for the banquet will be Paul Cousins, meteorologist for WBZ TV-4 in Boston, Massachusetts. The deadline for reservations is 14 February 1986. For more information contact Dawn Lowell, Box L-962, Lyndon State College, Lyndonville, VT 05851; telephone (802) 626-9371. 